\title{
Evaluation of a rapid and simple placental growth factor test in hypertensive disorders of pregnancy
}

\author{
Nóra Gullai, Balázs Stenczer, Attila Molvarec, Gergely Fügedi, Zoltán Veresh, Bálint Nagy and János Rigó Jr
}

The aim of this study was to investigate the diagnostic accuracy of the Triage placental growth factor (PIGF) assay, together with its prognostic efficiency in determining the need for preterm delivery in all forms of hypertensive disorders of pregnancy. A total of 130 pregnant women with a diagnosis of preeclampsia (PE: 23), HELLP syndrome (20), superimposed preeclampsia (SIPE: 17), chronic hypertension (CHT: 25), gestational hypertension (GHT: 18) and 27 normotensive pregnant controls were enrolled in this case-control study. A single blood sample was taken between 22 and 34 weeks of gestation, and the plasma was analyzed for PIGF using the Alere Triage PIGF assay. The PIGF levels found in all hypertensive disorder groups differed significantly from those observed in controls. There was a highly significant difference in PIGF concentrations between women with a pregnancy duration $<35$ weeks and controls. Using a gestational age-dependent threshold of $5 \%$ of normal, a positive PIGF test predicted delivery before 35 weeks in $93.7 \%$ of hypertensive women and delivery before 37 weeks in $90.5 \%$ of hypertensive women. A positive PIGF test identified the following proportions of hypertensive patients: $95.7 \%$ (PE), 95.0\% (HELLP syndrome), $82.4 \%$ (SIPE), $60.0 \%$ (CHT) and $44.4 \%$ (GHT). A positive PIGF test was associated with a significantly shorter duration of pregnancy (hazard ratio of 3.43 adjusted for the gestational age at the time of sample collection and hypertension with proteinuria). In conclusion, PIGF concentrations are significantly lower in all hypertensive disorders. A positive test using the Triage PIGF assay at 22-34 weeks of gestation predicts delivery before 37 weeks in women with both proteinuric and non-proteinuric hypertensive disorders of pregnancy.

Hypertension Research (2013) 36, 457-462; doi:10.1038/hr.2012.206; published online 17 January 2013

Keywords: chronic hypertension; gestational hypertension; placental growth factor; preeclampsia; superimposed preeclampsia

\section{INTRODUCTION}

Hypertensive disorders are among the most common complications of pregnancy, with a prevalence of $6-22 \% \%^{1,2}$ These conditions are responsible for the majority of maternal and fetal morbidity, and mortality. The American College of Obstetrics and Gynecology (ACOG) and the National High Blood Pressure Education Program Working Group on High Blood Pressure in Pregnancy (NHBPEP) $)^{1}$ have classified hypertension during pregnancy into the following groups: chronic hypertension (CHT), gestational hypertension (GHT), pre-eclampsia (PE) and pre-eclampsia superimposed on CHT (SIPE). A severe, but rare, syndrome associated with these diseases is hemolysis-elevated liver enzymes and low platelet count (HELLP) — which is usually associated with severe PE or SIPE.

There is a clinical need to provide selective antenatal care for women with those forms of the disease, who have an increased likelihood of progressing to an adverse fetal or maternal outcome. However, identifying which women with hypertension will progress to $\mathrm{PE}$ or an adverse outcome associated with an atypical form of PE is problematic and requires a more precise antenatal diagnosis than is available today. ${ }^{3,4}$ The criteria currently in use are based on nonspecific downstream features rather than pathologically relevant biomarkers that may be reflective of the progressive nature of the disease. Diagnosis can be confirmed only postnatally because one form can progress to another (for example, GHT to PE, CHT to SIPE, or every form to HELLP syndrome). Moreover, PE can have a variable clinical course, often requiring clinicians to diagnose PE in the absence of proteinuria. $^{5}$

Placental growth factor (PIGF) is a member of the vascular endothelial growth factor family. It is produced mainly by the placenta and has potent pro-angiogenic effects. In normal uncomplicated pregnancies, PIGF levels rise until the 32nd week, approximately, and then fall until delivery. In pregnancies complicated by PE before the 37th week with or without intrauterine growth restriction, PlGF levels are significantly lower. ${ }^{6,7}$

The imbalance of pro- and anti-angiogenic factors is a key focus of researchers examining the pathogenesis of PE. In PE patients, levels of the soluble vascular endothelial growth factor-receptor (sFlt-1), which binds circulating vascular endothelial growth factor and PlGF, are elevated; this in turn leads to decreases in the concentrations of the bioactive forms of these growth factors. This imbalance is thought to lead to the placental and systemic endothelial dysfunction that induces the clinical symptoms of the disease. The role of determining 
sFlt-1, PlGF and other angiogenic factor levels in maternal peripheral blood in the prediction and diagnosis of PE has been extensively studied in recent years. ${ }^{8-21}$ Unfortunately, there is still little information available about the levels of these factors in other forms of hypertension in pregnancy or their ability to predict outcomes. $^{22-27}$

In this study, we used a new method, the Alere Triage PlGF test, which measures non-complexed ('free') biologically active form of PIGF in the peripheral blood of hypertensive pregnant women. We examined its diagnostic accuracy for all forms of proteinuric and nonproteinuric hypertensive disorders of pregnancy measured before 35 weeks of gestation together with its prognostic efficiency in all forms of hypertensive disorders with respect to the need for preterm delivery. To our knowledge, this is the first paper to evaluate the clinical value of this new test in all subtypes of pregnancy-associated hypertensive disorders.

\section{METHODS}

Our study employed a case-control design. Twenty-three women with PE, 20 with HELLP syndrome (HELLP), 17 with SIPE, 25 with CHT, 18 with GHT, and 27 healthy, normotensive pregnant control subjects were enrolled. All subjects were Caucasian and resided in the same geographic area. Blood samples were taken in the First Department of Obstetrics and Gynecology, Semmelweis University, Budapest, Hungary, between May 2008 and October 2010. The blood draw occurred between the 22nd and 34th completed gestational weeks at the time of the first routine clinical blood test and was repeated only if women were reclassified. An interview was carried out with every subject after diagnosis and again 12 weeks after delivery, and, if necessary, reclassification was performed independent of the PlGF level. All subjects gave written informed consent prior to their involvement in the study. The study protocol was approved by the Regional and Institutional Committee of Science and Research Ethics of the Semmelweis University (TUKEB 52/2008). The study was conducted in accordance with the Declaration of Helsinki.

Hypertension was defined as a systolic blood pressure $(\mathrm{BP}) \geqslant 140 \mathrm{~mm} \mathrm{Hg}$ or a diastolic $\mathrm{BP} \geqslant 90 \mathrm{~mm} \mathrm{Hg}$ on two occasions at least six hours apart. We classified the subjects into the following groups according to the ACOG and NHBPEP definitions: CHT, GHT, PE and SIPE. A fifth group, HELLP, included women with hypertension, proteinuria and the syndrome of hemolysis, elevated liver enzymes and low platelet count.

$\mathrm{CHT}$ was diagnosed if high BP developed prior to pregnancy or before the 20th week of gestation or if hypertension persisted for more than 12 weeks postpartum. GHT was applied to women who developed new-onset hypertension after the 20th week of gestation in the absence of proteinuria. Women who later progressed to PE were excluded from this group, and following repeated blood draw, they were included in the PE group. PE was defined as hypertension and proteinuria ( $\geqslant 300 \mathrm{mg}$ per $24 \mathrm{~h}$, or $\geqslant+$ by urine dip-stick) with an onset after the 20th gestational week. Severe PE was diagnosed if one of the following occurred: systolic BP $\geqslant 160 \mathrm{~mm} \mathrm{Hg}$, diastolic BP $\geqslant 110 \mathrm{~mm}$ $\mathrm{Hg}$, proteinuria $\geqslant 5000 \mathrm{mg}$ per $24 \mathrm{~h}$ or $\geqslant+++$ by urine dipstick, partial HELLP syndrome, signs of renal insufficiency, pulmonary edema or threatening eclampsia. Early-onset PE was defined as the onset of the disease before 34 weeks of gestation. The diagnosis of HELLP syndrome was made based on characteristic laboratory findings (platelet count $<150 \mathrm{Gl}^{-1}$, SGOT and $\left.\mathrm{SGPT}>70 \mathrm{Ul}^{-1}, \mathrm{LDH}>600 \mathrm{Ul}^{-1}\right)$. All subjects in this group also met the criteria for severe PE. Women with CHT who developed proteinuria after 20 weeks of gestation were categorized as SIPE. Women were consecutively enrolled into the hypertensive groups. The control group consisted of healthy normotensive pregnant women without any maternal or fetal complications who were matched for maternal and gestational age at blood draw to the hypertensive groups. Women with multiple gestations were not enrolled in this study.

Our protocol for delivery dictates birth by Caesarean section, as clinically required, for women at any gestational age with HELLP syndrome, severe uncontrollable hypertension, severe proteinuria, with signs of renal insufficiency, pulmonary edema, threatening eclampsia (persistent headache and visual disturbance), low platelet count $\left(<100000 \mu \mathrm{l}^{-1}\right)$, elevated liver enzymes (SGOT $>70 \mathrm{Ul}^{-1}$ ) with epigastric pain, or evidence of fetal compromise (abnormal fetal flow or pathological CTG), severe intrauterine growth retardation or severe oligohydramnios. In the absence of any of these factors, we continue conservative management until the 37th completed gestational week.

After each blood draw, the EDTA-anticoagulated plasma samples were immediately centrifuged at $3000 \mathrm{~g}$ for $10 \mathrm{~min}$ at $4{ }^{\circ} \mathrm{C}$ and the supernatants were kept frozen at $-80^{\circ} \mathrm{C}$ until assayed.

Plasma was analyzed for PlGF using the Alere Triage PlGF assay (San Diego, CA, USA) according to the manufacturer's instructions. Using fluorescently labeled monoclonal antibodies against PlGF for PlGF quantification, this immunoassay is run with a single-use disposable plastic assay test cartridge in conjunction with the Triage Meter. Briefly, $250 \mu \mathrm{l}$ of thawed plasma (room temperature) is pipetted into the sample port of a new test cartridge. The cartridge is inserted into the meter, and the results are displayed in $\sim 15 \mathrm{~min}$ in $\mathrm{pg} \mathrm{ml}-1$. The cartridge contains chemistries for on-board positive and negative control systems. Control systems at the level of the cartridge and meter ensure that the quantitative PlGF result is valid. Calibration information is supplied by the manufacturer in the form of a lot-specific EPROM chip that is contained within each kit of devices. The measurable range of the assay is $12-3000 \mathrm{pg} \mathrm{ml}^{-1}$. Concentrations $<12 \mathrm{pg} \mathrm{ml}^{-1}$ are assigned values based on the calibration curve, but this value is displayed to the user as a qualitative result ' $<12 \mathrm{pg} \mathrm{ml}^{-1}$ '. A positive test was defined as a PlGF concentration $<5$ th percentile for gestational age with respect to the normal controls, as described in the product insert. Women were tested up to 34 completed weeks, as recommended in the manufacturer's product insert. The intra-/inter-assay coefficients of variation at mean concentrations of 85.2 and $1300 \mathrm{pg} \mathrm{ml}^{-1}$ were $12.1 / 12.8 \%$ and $11.7 / 13.2 \%$, respectively.

As PlGF levels increase in association with placental development until 32 weeks and then decrease towards term, gestational age-dependent cut-off levels were used to discriminate positive and negative results. The cutoff levels were based on the 5th percentile of the PlGF level in a normal healthy pregnant population, defined for the following gestational age intervals: $<19$ weeks, $56.2 \mathrm{pg} \mathrm{ml}^{-1}$; 19-23rd completed week: $62.9 \mathrm{pg} \mathrm{ml}^{-1}$; 24-28th completed week: $130 \mathrm{pg} \mathrm{ml}^{-1} ; 29-31 \mathrm{st}$ completed week: $128 \mathrm{pg} \mathrm{ml}^{-1}$, and 32-34th completed week: $70.4 \mathrm{pg} \mathrm{ml}^{-1} .7$

Data were also presented using an absolute cutoff threshold of $12 \mathrm{pg} \mathrm{ml}^{-1}$, that is, the lower limit of the assay, for comparison.

Descriptive statistics were used to present the clinical characteristics. Test positive fractions were calculated using two PlGF thresholds, as described above. Test positive fractions were calculated for subjects grouped by diagnosis and duration of pregnancy. Kaplan-Meier curves for duration of pregnancy were constructed for hypertensive patients grouped by PlGF test result (positive versus negative), and the associated hazard ratios were calculated based on univariate and multivariate Cox (proportional hazards) regression analyses. Boxplots were constructed, and the median, 25th and 75th percentiles were tabulated for the PlGF concentrations in subjects who were grouped by diagnosis and by duration of pregnancy, with $P$-values calculated using the Wilcoxon rank sum test.

\section{RESULTS}

In total, 130 women were available for analysis of a blood draw at $<35$ weeks, including 27 in the control group and 103 with hypertensive disorders of pregnancy. Seventy-four subjects had pregnancy durations of $<37$ weeks, and three of these gave birth early for reasons other than hypertensive disorders of pregnancy.

The clinical features of the study participants are presented in Table 1 . The majority of the PE women had an early-onset, severe form of the disease, requiring delivery before 37 weeks.

The number of women with positive PlGF tests, using a gestational age-dependent $5 \%$ threshold, is presented by diagnosis in Table 2 . The test positive fractions were highest for PE and HELLP and lower for SIPE. Data using an absolute cutoff of $12 \mathrm{pg} \mathrm{ml}^{-1}$ are also shown. Figure 1 (and Table 3 ) shows PlGF concentration by diagnosis. The 
Table 1 Clinical characteristics of study participants (GA $<35+0, N=130$ ) grouped as healthy controls and hypertensive patients by diagnosis. Continuous variables are reported as Median (IQR) and categorical variables are reported as $N(\%)$

\begin{tabular}{|c|c|c|c|c|c|c|}
\hline & Control $(\mathrm{n}=27)$ & $G H T(\mathrm{n}=18)$ & $C H T(\mathrm{n}=25)$ & $P E(\mathrm{n}=23)$ & $H E L L P(\mathrm{n}=20)$ & $\operatorname{SIPE}(\mathrm{n}=17)$ \\
\hline Maternal age (years) & $31(29-34)$ & $34(29-35)$ & $34(30-36)$ & $33(30-37)$ & $30(28-33)$ & $34(32-36)$ \\
\hline Pre-gestational BMI $\left(\mathrm{kg} \mathrm{m}^{-2}\right)$ & $21.4(19.4-24)$ & $\begin{array}{c}25.9(23.1- \\
30.8)^{* *}\end{array}$ & $\begin{array}{c}31.4(26.1- \\
35.9)^{* *}\end{array}$ & $25.6(22.4-29.6)^{*}$ & $23.9(22.2-33.5)^{*}$ & $24.4(21.9-30)^{*}$ \\
\hline Primiparas (\%) & $8(29.6)$ & $12(66.7)^{*}$ & $13(52)$ & $12(52.2)$ & $16(80)^{* *}$ & $8(47.1)$ \\
\hline $\begin{array}{l}\text { Systolic blood pressure at blood draw } \\
(\mathrm{mm} \mathrm{Hg})\end{array}$ & $110(109-120)$ & $154(146-158)^{* *}$ & $143(140-147)^{* *}$ & $169(160-178)^{* *}$ & $170(165-172)^{* *}$ & $164(151-170)^{* *}$ \\
\hline $\begin{array}{l}\text { Diastolic blood pressure at blood draw } \\
(\mathrm{mm} \mathrm{Hg})\end{array}$ & $70(66-75)$ & $96(94-100)^{* *}$ & $89(80-94)^{* *}$ & $109(100-114)^{* *}$ & $110(95-114)^{* *}$ & $104(96-112)^{* *}$ \\
\hline GA at disease onset (weeks) & NA & $28(26-33)$ & NA & $30(27-32)$ & $30(28-32)$ & $30(28-31)$ \\
\hline GA at blood draw (weeks) & $31(29-33)$ & $33(31-34)$ & $33(30-34)$ & $31(28-33)$ & $31(28-32)$ & $31(28-32)$ \\
\hline GA at delivery (weeks) & $39(38-40)$ & $38(36-39)$ & $37(34-38)^{* *}$ & $31(28-34)^{* *}$ & $31(28-32)^{* *}$ & $32(30-36)^{* *}$ \\
\hline Blood draw to delivery time interval (days) & $55(40-70)$ & $29(21-51)^{*}$ & $21(4-45)^{* *}$ & $1(0-3)^{* *}$ & $0(0-1)^{* *}$ & $8(3-25)^{* *}$ \\
\hline Premature birth (\%) & $3(11.1)$ & 7 (38.9) & $11(44)^{*}$ & $22(95.7)^{* *}$ & $20(100)^{* *}$ & $14(82.4)^{* *}$ \\
\hline Fetal birthweight (grams) & $\begin{array}{l}3270(3100- \\
3560)\end{array}$ & $\begin{array}{c}3280(2150- \\
3860)\end{array}$ & $\begin{array}{l}2710(2130- \\
3370)^{*}\end{array}$ & $\begin{array}{c}1330(990- \\
1740)^{* *}\end{array}$ & $\begin{array}{c}1265(940- \\
1575)^{* *}\end{array}$ & $\begin{array}{c}1750(1100- \\
2560)^{* *}\end{array}$ \\
\hline Fetal growth restriction (\%) & $0(0)$ & $3(16.7)$ & $2(8)$ & $10(43.5)^{* *}$ & $6(30)^{*}$ & $5(29.4)^{*}$ \\
\hline Early-onset PE (\%) & $0(0)$ & $0(0)$ & $0(0)$ & $21(91.3)^{* *}$ & $17(85)^{* *}$ & $16(94.1)^{* *}$ \\
\hline Severe PE (\%) & $0(0)$ & $0(0)$ & $0(0)$ & $22(95.7)^{* *}$ & $20(100)^{* *}$ & $11(64.7)^{* *}$ \\
\hline
\end{tabular}

Abbreviation: NA, not applicable.

Statistical significance of hypertensive groups compared to controls: ${ }^{*} P<0.05,{ }^{* *} P<0.001$.

Table 2 PIGF Test Positive Fraction in healthy controls, hypertensive patients by diagnosis, or hypertensive patients by length-of-pregnancy. N is the number of subjects in each group and $\mathbf{N}+$ is the number who tested positive in each group

\begin{tabular}{|c|c|c|c|c|c|c|c|c|c|}
\hline \multirow[b]{2}{*}{ Group } & \multirow[b]{2}{*}{$\mathrm{N}$} & \multicolumn{4}{|c|}{ Below the 5th percentile } & \multicolumn{4}{|c|}{$\leqslant 12 \mathrm{pg} \mathrm{m}^{-1}$} \\
\hline & & $\mathrm{N}+$ & Fraction & $95 \% \mathrm{LCl}$ & $95 \% \cup C l$ & $\mathrm{~N}+$ & Fraction & $95 \% \mathrm{LCl}$ & $95 \% \cup C$ \\
\hline GHT & 18 & 8 & 0.444 & 0.215 & 0.692 & 3 & 0.167 & 0.036 & 0.414 \\
\hline CHT & 25 & 15 & 0.600 & 0.387 & 0.789 & 5 & 0.200 & 0.068 & 0.407 \\
\hline $\mathrm{PE}$ & 23 & 22 & 0.957 & 0.781 & 0.999 & 18 & 0.783 & 0.563 & 0.925 \\
\hline $\mathrm{LP}<35+0$ & 63 & 59 & 0.937 & 0.845 & 0.982 & 48 & 0.762 & 0.638 & 0.860 \\
\hline LP 35-37 & 11 & 8 & 0.727 & 0.390 & 0.940 & 1 & 0.091 & 0.002 & 0.413 \\
\hline$L P>36+6$ & 29 & 11 & 0.379 & 0.207 & 0.577 & 2 & 0.069 & 0.008 & 0.228 \\
\hline$L P<37$ & 74 & 67 & 0.905 & 0.815 & 0.961 & 49 & 0.662 & 0.543 & 0.768 \\
\hline$L P<37^{a}$ & 71 & 67 & 0.944 & 0.862 & 0.984 & 49 & 0.690 & 0.569 & 0.795 \\
\hline
\end{tabular}

aExcludes three patients who delivered prior to 37 weeks for reasons unrelated to hypertension (two due to pPROM and one due to bradycardia of fetus).

PlGF concentrations of women with hypertensive disorders of pregnancy were significantly different from the control group for all diagnoses.

Table 2 shows the number of women with positive PlGF tests by duration of pregnancy. A pregnancy duration of $<37$ weeks was predicted using a positive PlGF test at blood draw in $90.5 \%$ of women $(n=74)$ and was higher after the three subjects who had a reason for delivery other than hypertensive disorders of pregnancy were removed $(n=71)$. Specifically, two of these subjects in the CHT group with premature rupture of membranes and one subject in the CHT group with fetal bradycardia were removed; all three of these patients tested negative on the PlGF test.

A pregnancy duration of $<35+0$ weeks was predicted using a positive PlGF test at blood draw in $93.7 \%$ of women. Figure 2 (and
Table 4) shows PlGF concentration by duration of pregnancy. PlGF concentrations in women with pregnancy durations of $<35$ weeks or between 35 and 37 weeks were significantly different from those in women with pregnancy durations of 37 weeks or more.

Figure 3, which shows the Kaplan-Meier curves for the duration of pregnancy in hypertensive subjects comparing the positive and negative PlGF groups, demonstrates that the duration of pregnancy was much shorter for women with a positive PlGF, regardless of whether a cutoff of the 5th percentile or an absolute cutoff of $12 \mathrm{pg} \mathrm{ml}^{-1}$ was used. Table 5 shows the results of univariate and multivariate Cox regression analyses to predict pregnancy duration in women with hypertensive disorders $(N=103)$. The univariate hazard ratios for positive PlGF tests (as compared to negative tests) were statistically significant and became stronger when adjusted for GA at 


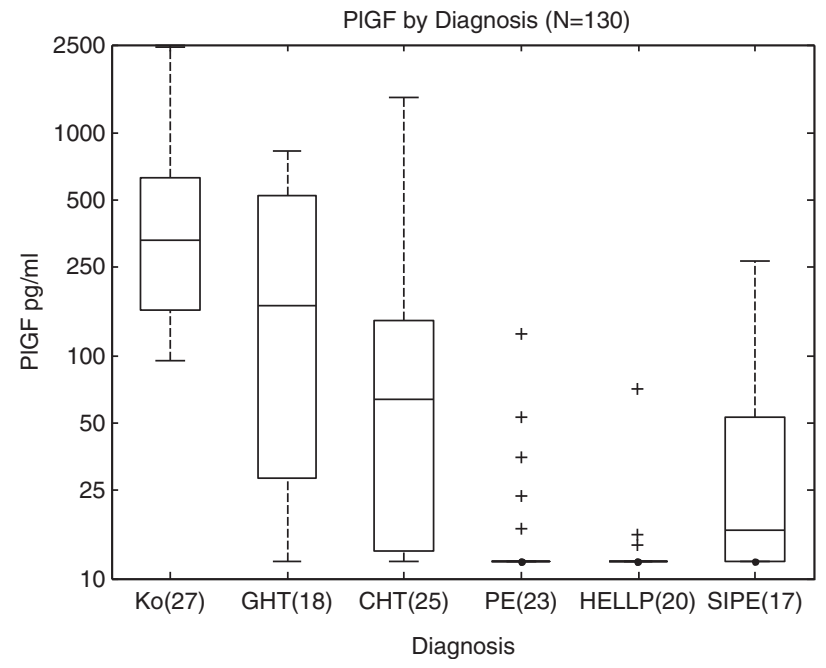

Figure 1 Boxplot of PIGF concentration by diagnosis $(n=130)$.

Table 3 Descriptive statistics of PIGF concentration ( $\mathrm{pg} \mathrm{ml}^{-1}$ ) by diagnosis $(n=130)$ where Ko designates the control group

\begin{tabular}{lccccc}
\hline Group & N & Median & 25th\% & 75th\% & P-value* \\
\hline Ko & 27 & 331 & 163 & 633 & N/A \\
GHT & 18 & 168 & 28 & 527 & 0.0199 \\
CHT & 25 & 64 & 13 & 145 & 0.0000 \\
PE & 23 & 12 & 12 & 12 & 0.0000 \\
HELLP & 20 & 12 & 12 & 12 & 0.0000 \\
SIPE & 17 & 16 & 12 & 53 & 0.0000 \\
\hline
\end{tabular}

* $P$-value compared with control group $(\mathrm{Ko})$

PIGF by diagnosis $(N=130), \mathrm{GA}<35$.

blood draw. The multivariate analysis shows that the PlGF test was a significant predictor of duration of pregnancy, even when adjusted for hypertension with proteinuria.

As shown in Table 2, five subjects with proteinuric hypertension had a negative PlGF result at blood draw. Specifically, three women with SIPE had a PlGF level of 123 (33rd week), 149 (34th week) and 265 (33rd week) $\mathrm{pg} \mathrm{ml}^{-1}$; all of these women had mild diseases without any placental functional abnormalities, delivering neonates with normal birth weights at 32,19 and 23 days after the blood draw, in the 38th, 37th and 36th weeks, respectively. One woman with HELLP syndrome and a negative test result had a PlGF level of $70.9 \mathrm{pg} \mathrm{ml}^{-1}$, which was marginally higher than the test cutoff $\left(70.4 \mathrm{pg} \mathrm{ml}^{-1}\right)$. This woman had moderately elevated BP (highest $\mathrm{BP}$ of 140 per $90 \mathrm{~mm} \mathrm{Hg}$ ) and mild proteinuria (maximum ++ by urine dipstick) without any sign of placental insufficiency and delivered in the same week of diagnosis and blood draw (week 34). In the case of the woman with PE and a negative test result, the PlGF level of $126 \mathrm{pg} \mathrm{ml}^{-1}$ (33rd week) was above the test cutoff $\left(70.4 \mathrm{pg} \mathrm{ml}^{-1}\right.$ ). This woman had a moderately elevated BP (highest $\mathrm{BP}$ of 140 per $90 \mathrm{~mm} \mathrm{Hg}$ ) and mild proteinuria (maximum ++ by urine dipstick) without any sign of placental insufficiency and delivered in the 37th week, six weeks after the diagnosis of PE was made.

All women with PE who delivered before 37 weeks were testpositive, and the one woman with $\mathrm{PE}$ who delivered at 37 weeks was test-negative.

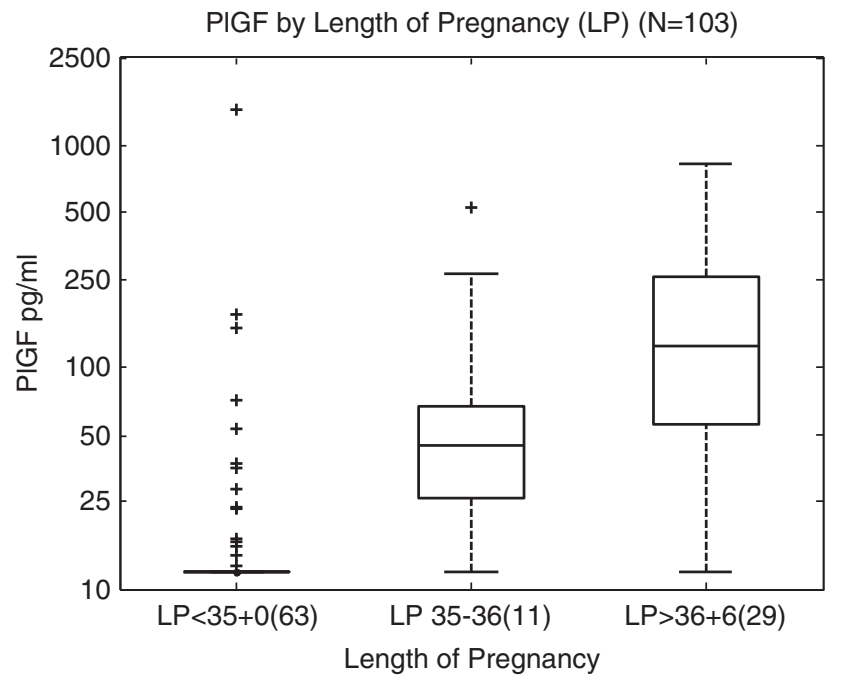

Figure 2 Boxplot of PIGF concentration by duration-of-pregnancy group ( $n=103$, excludes controls).

Table 4 Descriptive statistics of PIGF concentration ( $\mathrm{pg} \mathrm{ml}^{-1}$ ) by length-of-pregnancy group in hypertensive subjects $(n=103)$

\begin{tabular}{lccccc}
\hline Group & N & Median & 25th\% & 75th\% & P-value* \\
\hline LP $<35+0$ & 63 & 12 & 12 & 12 & 0.0000 \\
LP 35-36 & 11 & 44 & 26 & 67 & 0.0455 \\
LP $>36+6$ & 29 & 126 & 55 & 259 & N/A \\
\hline
\end{tabular}

*P-value compared with $\mathrm{LP}>36+6$.

Length-of-pregnancy (LP) was categorized as three groups, $<35+0,35+0-36+6$, and $>36+6$ in units of weeks + days.

Of the 40 women with non-proteinuric hypertension, 13 of the 15 women who delivered before 37 weeks had positive PlGF test results. In the case of the two women who tested negative for PlGF, one had a PlGF level of $70.5 \mathrm{pg} \mathrm{ml}^{-1}$ (34th week), which was marginally above the test cutoff $\left(70.4 \mathrm{pg} \mathrm{ml}^{-1}\right)$, and delivered an infant weighing $2660 \mathrm{~g}$ in the 36th week by Caesarean section; the other woman had a PlGF level of $527 \mathrm{pg} \mathrm{ml}^{-1}$ (33rd week), which was significantly above the test cutoff $\left(70.4 \mathrm{pg} \mathrm{ml}^{-1}\right)$, and delivered an infant weighing 4080 grams in the 36 th week via Caesarean section.

\section{DISCUSSION}

This study was designed to assess the performance of the Alere Triage PlGF test, a new rapid test for measuring non-complexed PlGF levels in maternal peripheral blood. Our study population consisted of women with PE, SIPE, HELLP syndrome, CHT, GHT and healthy pregnant control subjects. We evaluated the prognostic value of the test in predicting delivery before 35 and 37 weeks and in determining the overall duration of pregnancy. We also compared the test-positive fraction of PlGF in all types of hypertensive disorders of pregnancy.

Hypertensive disorders of pregnancy are a diverse group of gestational conditions with a high prevalence and significance. Fetal and maternal outcomes, as well as the severity of the various subtypes, can be extremely diverse; therefore, their differentiation can have a major clinical impact. ${ }^{1}$ Several papers have reported that placental growth factor, alone or in combination with other angiogenic agents, is a reliable marker for the diagnosis of PE and that its levels in the 


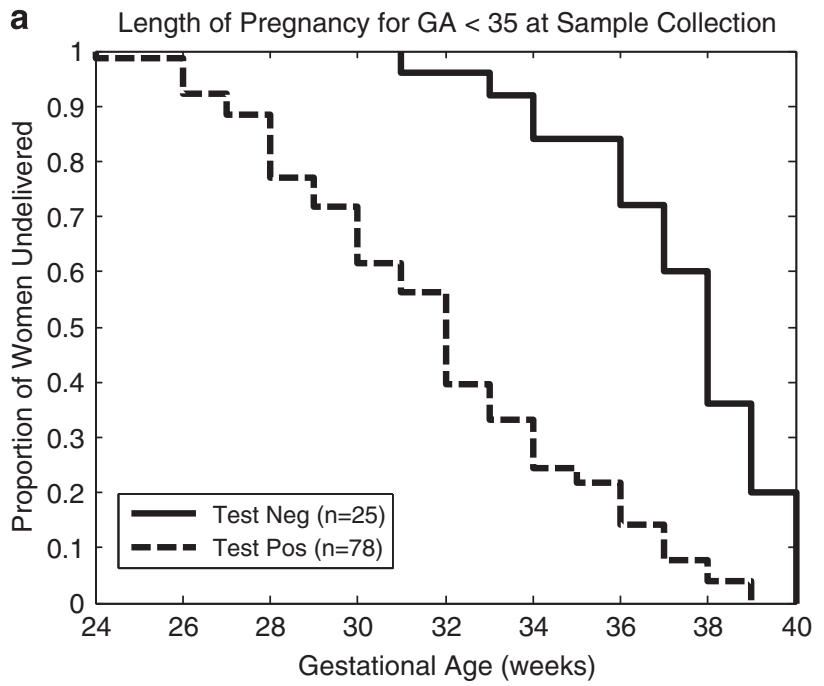

b Length of Pregnancy for GA $<35$ at Sample Collection

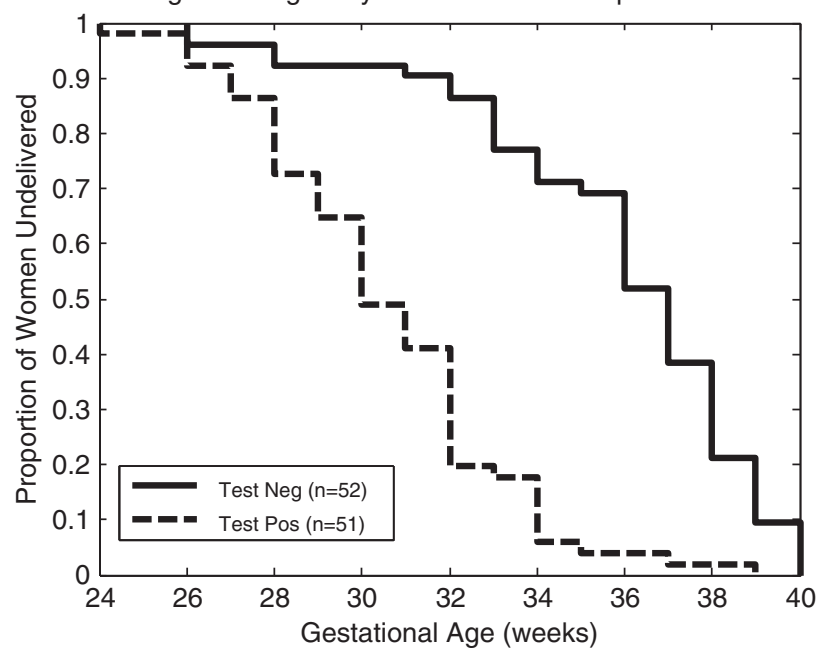

Figure 3 (a) Duration-of-pregnancy KM curve $(n=103)$ at a 5th percentile cutoff. (b) Duration-of-pregnancy KM curve $(n=103)$ at a $12 \mathrm{pg} \mathrm{ml}^{-1}$ cutoff. maternal circulation show a strong correlation with disease severity. ${ }^{6-19,21,28}$ We know less about the usefulness of the determination of PlGF levels in other types of hypertension. ${ }^{23-25}$

We concur with previous findings that plasma PlGF levels are decreased in hypertensive women. The PlGF concentrations that we observed were below the test cutoff in almost every subject with hypertension accompanied by proteinuria, as well as in around threefifths of hypertensive subjects without proteinuria and in 1 of the 27 control subjects.

Earlier studies evaluating the diagnostic accuracy of the sFlt-1/PlGF ratio in PE showed sensitivity and specificity values from 74 and 89 to 100 and $95 \%$, respectively, with better results in the early-onset compared with the late-onset forms of PE. ${ }^{18,26}$ Redman et al. ${ }^{17}$ compared the performance of the Alere Triage PlGF test with that of the R\&D Systems Quantikine PlGF test (Minneapolis, MN, USA) and concluded that the Triage PlGF test was better able to discriminate cases from controls. Similarly, Benton et al. ${ }^{29}$ found that, compared with the Elecsys sFlt-1/PlGF immunoassay (Roche, Mannheim, Germany), the Triage PlGF has superior discriminatory power in diagnosing $\mathrm{PE}$ with an onset before $35+0$ weeks of gestation.

In our trial, using samples obtained before 35 weeks, the Triage PlGF had high sensitivities in the detection of PE (95.7\%), HELLP syndrome $(95.0 \%)$ and SIPE $(82.4 \%)$. Negative and positive predictive values were not calculated because the prevalence of the control group was not representative of a real target population for the test. Recently, Sunderji et al. ${ }^{16}$ did not find significant differences in the PlGF levels of 18 chronic hypertensive subjects compared with 388 healthy pregnant women (364 (197-587) vs. 447 (396-520) $\left.\mathrm{pg} \mathrm{ml}^{-1}, P=0.14\right)$. They concluded that the ratio of sFlt- 1 to PlGF is not affected by pre-existing hypertension and is therefore a useful indicator of SIPE.

We found that PlGF identifies women at risk of early delivery in women with all hypertensive disorders of pregnancy, including those with CHT who do not progress to SIPE. The proportion of subjects with a positive test result was higher in the SIPE group than in the CHT group.

In hypertensive subjects, there was a strong association between PlGF level and the overall duration of pregnancy, even after adjusting for the gestational age at sample collection and a diagnosis of

Table 5 Hazard ratios for PIGF test based on univariate and multivariate Cox regression to predict length-of-pregnancy in hypertensive patients $(N=103)$

\begin{tabular}{|c|c|c|c|c|c|c|}
\hline \multirow[b]{2}{*}{ Variable } & \multicolumn{3}{|c|}{ Below the 5th percentile } & \multicolumn{3}{|c|}{$\leqslant 12 p g m l^{-1}$} \\
\hline & Hazard ratio & $95 \% \mathrm{LCl}$ & $95 \% \cup C l$ & Hazard ratio & $95 \% \mathrm{LCl}$ & $95 \% \cup C I$ \\
\hline \multicolumn{7}{|c|}{ Univariate Cox Regression of PIGF } \\
\hline Test-positive & 3.65 & 2.18 & 6.10 & 4.41 & 2.81 & 6.93 \\
\hline \multicolumn{7}{|c|}{ Multivariate Cox Regression of PIGF and GA at sample collection } \\
\hline Test-positive & 4.63 & 2.71 & 7.89 & 5.79 & 3.48 & 9.62 \\
\hline GA(sample) & 0.83 & 0.77 & 0.90 & 0.84 & 0.78 & 0.91 \\
\hline \multicolumn{7}{|c|}{ Multivariate Cox Regression of PLGF, GA at sample collection, and PE, HELLP and SIPE diagnoses } \\
\hline Test positive & 3.43 & 1.97 & 5.98 & 3.91 & 2.23 & 6.86 \\
\hline GA(sample) & 0.84 & 0.77 & 0.91 & 0.83 & 0.76 & 0.90 \\
\hline PE,HELLP,SIPE & 3.83 & 2.26 & 6.49 & 3.49 & 1.98 & 6.15 \\
\hline
\end{tabular}

PIGF test positive is defined as either $<5$ th percentile of normal, or $\leqslant 12 \mathrm{pg} \mathrm{ml}^{-1}$ (lower limit of the assay). The $P$-values for all hazard ratios in the table were $<0.0001$. 
hypertension with proteinuria. This finding indicates a good prognostic property of the test, as low PlGF levels seem to indicate more severe diseases not only in PE but also in hypertension forms without proteinuria. Proteinuria is currently used as a diagnostic sign, but its measurement after diagnosis has less value, as the quantification of proteinuria has not been shown to be related to outcome.

The real potential clinical impact of these findings is that a negative PlGF test could identify a subgroup of women with chronic or GHT who are at low risk for progression into PE or SIPE. These women may require less intensive clinical attendance.

A positive PlGF test correctly identified hypertension and proteinuric pregnancies with $\mathrm{PE}$ and stratified women with non-proteinuric hypertension into those likely to require urgent delivery and those likely to continue safely to term. Our study supports a need to improve the specificity of the definitions of the different forms of hypertension in pregnancy and to consider the inclusion of pathophysiologically relevant biomarkers, such as PlGF, alongside proteinuria and laboratory findings.

One weakness of our study was its retrospective design and low number of cases. In addition, the blood samples were collected only at 22-34 weeks of gestation, but not thereafter. There is a need for prospective studies to evaluate women throughout gestation to determine the predictive value of the Triage PlGF test in hypertensive disorders of pregnancy.

In conclusion, our study suggests that the Triage PlGF test provides valuable information relating to the diagnosis and predicted duration of pregnancy for women with all forms of hypertensive disorders before a gestational age of 35 weeks. This test is available at the bedside to augment clinical decisions regarding management of the pregnancy.

\section{CONFLICT OF INTEREST}

The authors declare no conflict of interest.

\section{ACKNOWLEDGEMENTS}

This work was supported by the János Bolyai Research Scholarship of the Hungarian Academy of Sciences (AM). Ken Kupfer, of Alere International, provided additional analyses of the data, and Fiona Milne, freelance medical writer, helped with editing the manuscript.

1 National High Blood Pressure Education Program Working Group on High Blood Pressure in Pregnancy. Report of the National High Blood Pressure Education Program Working Group on High Blood Pressure in Pregnancy. Am J Obstet Gynecol 2000; 183 S1-S22.

2 Walker JJ. Pre-eclampsia. Lancet 2000; 356: 1260-1265.

3 Douglas KA, Redman CW. Eclampsia in the United Kingdom. BMJ 1994; 309 1395-1400.

4 Sibai BM, Ramadan MK, Usta I, Salama M, Mercer BM, Friedman SA. Maternal morbidity and mortality in 442 pregnancies with hemolysis, elevated liver enzymes, and low platelets (HELLP syndrome). Am J Obstet Gynecol 1993; 169: 1000-1006.

5 Hauth JC. Preeclampsia-Eclampsia, In Chesley's Hypertensive Disorders in Pregnancy 2nd (eds). Appleton \& Lange, Stamford, Connecticut, 1999, pp 169-199.

6 Levine RJ, Maynard SE, Qian C, Lim KH, England LJ, Yu KF, Schisterman EF, Thadhan R, Sachs BP, Epstein FH, Sibai BM, Sukhatme VP, Karumanchi SA. Circulating angiogenic factors and the risk of pre-eclampsia. N Engl J Med 2004; 350: 672-683.

7 Knudsen UB, Kronborg CS, von Dadelszen P, Kupfer K, Lee S-W, Vittinghus E, Allen JG, Redman CW. A single rapid point of care placental growth factor determination as an aid in the diagnosis of preeclampsia. Pregn Hypertens 2012; 2: 8-15.

8 Ohkuchi A, Hirashima C, Matsubara S, Takahashi K, Matsuda Y, Suzuki M. Threshold of soluble fms-like tyrosine kinase 1/placental growth factor ratio for the imminent onset of preeclampsia. Hypertension 2011; 58: 859-866.
9 Hertig A, Berkane N, Lefevre G, Toumi K, Marti HP, Capeau J, Uzan S, Rondeau E. Maternal serum sFlt1 concentration is an early and reliable predictive marker of preeclampsia. Clin Chem 2004; 50: 1702-1703.

10 McKeeman GC, Ardill JE, Caldwell CM, Hunter AJ, McClure N. Soluble vascular endothelial growth factor receptor-1 (sFIt-1) is increased throughout gestation in patients who have preeclampsia develop. Am J Obstet Gynecol 2004; 191: 1240-1246.

11 Shibata E, Rajakumar A, Powers RW, Larkin RW, Gilmour C, Bodnar LM, Crombleholme WR, Ness RB, Roberts JM, Hubel CA. Soluble fms-like tyrosine kinase 1 is increased in preeclampsia but not in normotensive pregnancies with small-for-gestational-age neonates: relationship to circulating placental growth factor. J Clin Endocrinol Metab 2005; 90: 4895-4903.

12 Kim SY, Ryu HM, Yang JH, Kim MY, Han JY, Kim JO, Chung JH, Park SY, Lee MH, Kim DJ. Increased sFIt-1 to PIGF ratio in women who subsequently develop preeclampsia. J Korean Med Sci 2007; 22: 873-877.

13 Torry DS, Wang HS, Wang TH, Caudle MR, Torry RJ. Preeclampsia is associated with reduced serum levels of placenta growth factor. Am J Obstet Gynecol 1998; 179: 1539-1544.

14 Reuvekamp A, Velsing-Aarts FV, Poulina IE, Capello JJ, Duits AJ. Selective deficit of angiogenic growth factors characterises pregnancies complicated by pre-eclampsia. $\mathrm{Br}$ J Obstet Gynaecol 1999; 106: 1019-1022.

15 Livingston JC, Chin R, Haddad B, McKinney ET, Ahokas R, Sibai BM. Reductions of vascular endothelial growth factor and placental growth factor concentrations in severe preeclampsia. Am J Obstet Gynecol 2000; 183: 1554-1557.

16 Sunderji S, Gaziano E, Wothe D, Rogers LC, Sibai B, Karumanchi SA, Hodges-Savola C. Automated assays for sVEGF R1 and PIGF as an aid in the diagnosis of preterm preeclampsia: a prospective clinical study. Am J Obstet Gynecol 2010; 202: 40.e1-40.e7.

17 Redman C, Lodge T, Meacher H, Marks C, Simms C, Sargent I. Triage ${ }^{\circledR}$ PIGF test: point-of-care assay of plasma placental growth factor to diagnose preeclampsia. Adv Perinat Med 2010, Proceedings(ECPM) 181-185.

18 Ohkuchi A, Hirashima C, Suzuki H, Takahashi K, Yoshida M, Matsubara S, Suzuki M. Evaluation of a new and automated electrochemiluminescence immunoassay for plasma sFIt-1 and PIGF levels in women with preeclampsia. Hypertens Res 2010; 33: 422-427.

19 Kusanovic JP, Romero R, Chaiworapongsa T, Erez O, Mittal P, Vaisbuch E, Mazaki-Tovi S, Gotsch F, Edwin SS, Gomez R, Yeo L, Conde-Agudelo A, Hassan SS. A prospective cohort study of the value of maternal plasma concentrations of angiogenic and antiangiogenic factors in early pregnancy and midtrimester in the identification of patients destined to develop preeclampsia. J Matern Fetal Neonatal Med 2009; 22: 1021-1038.

$20 \mathrm{Lim}$ JH, Kim SY, Park SY, Yang JH, Kim MY, Ryu HM. Effective prediction of preeclampsia by a combined ratio of angiogenesis-related factors. Obstet Gynecol 2008; 111: 1403-1409.

21 Molvarec A, Szarka A, Walentin S, Szucs E, Nagy B, Rigo Jr J. Circulating angiogenic factors determined by electrochemiluminescence immunoassay in relation to the clinical features and laboratory parameters in women with pre-eclampsia. Hypertens Res 2010; 33: 892-898.

22 Powers RW, Jeyabalan A, Clifton RG, Van Dorsten P, Hauth JC, Klebanoff MA Lindheimer MD, Sibai B, Landon M, Miodovnik M. Eunice Kennedy Shriver National Institute of Child Health Human Development Maternal-Fetal Medicine Units Network. Soluble fms-Like tyrosine kinase 1 (sFlt1), endoglin and placental growth factor (PIGF) in preeclampsia among high risk pregnancies. PLoS One 2010; 5: e13263.

23 Nadarajah VD, Min RG, Judson JP, Jegasothy R, Ling EH. Maternal plasma soluble fmslike tyrosine kinase-1 and placental growth factor levels as biochemical markers of gestational hypertension for Malaysian mothers. J Obstet Gynaecol Res 2009; 35 . 855-863.

24 Khalil A, Muttukrishna S, Harrington K, Jauniaux E. Effect of antihypertensive therapy with alpha methyldopa on levels of angiogenic factors in pregnancies with hypertensive disorders. PLoS One 2008; 3: e2766.

25 Noori M, Donald AE, Angelakopoulou A, Hingorani AD, Williams DJ. Prospective study of placental angiogenic factors and maternal vascular function before and after preeclampsia and gestational hypertension. Circulation 2010; 122: 478-487.

26 Verlohren S, Galindo A, Schlembach D, Zeisler H, Herraiz I, Moertl MG, Pape J, Dudenhausen JW, Denk B, Stepan H. An automated method for the determination of the sFIt-1/PIGF ratio in the assessment of preeclampsia. Am J Obstet Gynecol 2010; 202: 161.e1-161.e11.

27 Chaiworapongsa T, Romero R, Savasan ZA, Kusanovic JP, Ogge G, Soto E, Dong Z, Tarca A, Gaurav B, Hassan SS. Maternal plasma concentrations of angiogenic/antiangiogenic factors are of prognostic value in patients presenting to the obstetrical triage area with the suspicion of preeclampsia. J Matern Fetal Neonatal Med 2011; 24: 1187-1207.

28 De Vivo A, Baviera G, Giordano D, Todarello G, Corrado F, Endoglin D'AnnaR. PIGF and sFlt-1 as markers for predicting pre-eclampsia. Acta Obstet Gynecol Scand 2008; 87 837-842.

29 Benton S, Hu Y, Xie F, Kupfer K, Lee SW, Magee L, von Dadelszen P. Angiogenic factors as diagnostic tests for preeclampsia: a performance comparison between two commercial immunoassays. Am J Obstet Gynecol 2011; 205: 469.e1-469.e8. 